\title{
Carryover of bovine leukemia virus antibodies in samples from shared milk meters
}

\author{
O. A. Nekouei, ${ }^{1}$ J. Sanchez, and G. P. Keefe \\ Department of Health Management, Atlantic Veterinary College, University of Prince Edward Island, Charlottetown, Prince Edward Island, \\ Canada C1A 4P3
}

\section{ABSTRACT}

Screening for infectious diseases of cattle using milk from the dairy herd improvement (DHI) sampling process is very convenient. However, when samples from shared milk meters are used, carryover of antibodies or other diagnostic targets can complicate the interpretation of the diagnostic test results for diseases, including bovine leukosis. The objectives of this study were (1) to assess the potential for carryover of antibodies against bovine leukemia virus (BLV) in milk samples obtained from shared meters, and (2) to determine if adjustment of the diagnostic test cut-off value would improve the test characteristics for meter-collected milk ELISA results. Eight dairy farms were randomly selected from herds with a wide range of BLV prevalence levels in Prince Edward Island, Canada. Within each chosen farm, 2 to 4 milk meters were randomly selected. During the routine procedures of DHI sampling, 2 simultaneous milk samples, 1 hand-collected at the beginning of milking (after udder preparation) and the other from the corresponding milk meter, were taken from all lactating cows $(\mathrm{n}=236)$ that were milked at the selected meters $(\mathrm{n}=26)$. The sequence of cows using each meter was recorded. All samples were tested for BLV antibodies using a commercial indirect ELISA. Antibody carryover potential was assessed in metercollected samples that were preceded by other cows using the same meters. Applying the hand-collected sample results as our reference standard, a new cut-off was defined for meter-collected samples to optimize the test characteristics. At the standard cut-off value of the diagnostic test, 110 (46.6\%) of the hand-collected and $136(57.6 \%)$ of the meter-collected samples were positive. For low-titer cows (e.g., true negatives), the likelihood of antibody carryover significantly increased as the titer of preceding cows increased, whereas this change was not substantial for high-titer cows. The odds of obtaining false diagnoses in meter-positive samples

Received October 28, 2014.

Accepted April 9, 2015.

${ }^{1}$ Corresponding author: onekouei@upei.ca became larger with increase in the titer of preceding cows. A suspicious category for meter ELISA results was defined, and a retest was recommended for the cows falling into this category. This strategy effectively assisted in reducing the number of consequent falsepositive results. When DHI-collected samples are used, carryover can affect the interpretation of dichotomous test results and may require adjustment of assay cut-off values.

Key words: carryover, milk meter, dairy herd improvement, bovine leukemia virus

\section{INTRODUCTION}

Enzootic bovine leukosis (EBL) is an economically important infection of dairy cattle worldwide, which is caused by bovine leukemia virus (BLV). In North America, prevalence of the infection has been high and appears to have a rising trend (Samagh and Kellar, 1982; Richardson and Macaulay, 1992; Sargeant et al., 1997; VanLeeuwen et al., 2001; VanLeeuwen et al., 2005; VanLeeuwen et al., 2006; Bartlett et al., 2014). For instance, in Prince Edward Island, Canada, herd-level prevalence of BLV was $49.2 \%$ in 1989 (Richardson and Macaulay, 1992), increased to $63.3 \%$ in 1998 (VanLeeuwen et al., 2001), and is currently at $90 \%$ based on a survey of bulk tank milk in all dairy herds in the province completed in 2013 (O. A. Nekouei, unpublished data). However, no broad-based national program for controlling EBL in Canada and the United States has been implemented.

Several studies have recently been conducted to estimate the prevalence of BLV infection and define cost-effective screening tools to be applied in control programs. Monitoring meter-collected milk samples, obtained from the DHI process has become one of the standard and economically efficient procedures for screening for important infectious diseases in dairy cattle, such as bovine viral diarrhea, Johne's disease, and EBL (Houe et al., 1995; Attalla et al., 2010; Sorge et al., 2011). Among the available commercial tests for detection of antibodies against BLV, milk ELISA is a desirable method in large-scale herd surveillance 
Table 1. Herd characteristics and milk-ELISA results for antibodies against bovine leukemia virus (BLV) on 8 study farms from Prince Edward Island, Canada

\begin{tabular}{|c|c|c|c|c|c|c|}
\hline Farm & $\begin{array}{l}\text { Prevalence } \\
\text { level }^{1}\end{array}$ & $\begin{array}{l}\text { Lactating } \\
\text { herd size }\end{array}$ & $\begin{array}{c}\text { Selected } \\
\text { meters }\end{array}$ & $\begin{array}{c}\text { Tested } \\
\text { cows }\end{array}$ & $\begin{array}{l}\text { Positives in } \\
\text { meter }^{2}\end{array}$ & $\begin{array}{l}\text { Positives } \\
\text { in hand }^{2}\end{array}$ \\
\hline 1 & Low & 49 & 3 & 27 & 0 & 0 \\
\hline 2 & Low & 83 & 4 & 28 & 4 & 4 \\
\hline 3 & Medium & 57 & 4 & 22 & 15 & 11 \\
\hline 4 & Medium & 46 & 2 & 12 & 5 & 4 \\
\hline 5 & High & 62 & 3 & 30 & 24 & 23 \\
\hline 6 & High & 126 & 4 & 48 & 35 & 25 \\
\hline 7 & Very high & 76 & 3 & 37 & 27 & 23 \\
\hline 8 & Very high & 64 & 3 & 32 & 24 & 20 \\
\hline Total & - & 563 & 26 & 236 & 136 & 110 \\
\hline
\end{tabular}

${ }^{1}$ Predicted levels of within-herd prevalence of BLV based on a companion study (O. A. Nekouei, unpublished data).

${ }^{2}$ Number of cows testing positive at the recommended ELISA cut-off of 10 (percent positivity).

because milk sampling during the DHI process is much more convenient and cost-effective than serum collection (Erskine et al., 2012).

With respect to sequential milk samples, "carryover" denotes the risk for inclusion of some residual milk from the previous cows in the subsequent samples (Ordolff, 1997; Løvendahl and Bjerring, 2006). With increasing utilization of DHI diagnostic services on metercollected samples, a legitimate concern exists regarding carryover or cross contamination of milk samples from shared milking equipment. The objectives of our study were (1) to assess the potential for carryover of BLV antibodies in milk samples obtained from shared meters, and (2) to determine if adjustment of the diagnostic test cut-off value would improve the test characteristics for meter-collected milk ELISA results.

\section{MATERIALS AND METHODS}

\section{Sample Collection}

Based on a companion study using bulk tank milk samples from all dairy farms in Prince Edward Island, Canada, all DHI-participant farms were assigned into 5 separate categories of BLV infection level: (1) assumed uninfected, (2) low prevalence, (3) medium prevalence, (4) high prevalence, and (5) very high prevalence farms (O. A. Nekouei, unpublished data). In July 2013, 2 farms were randomly selected from each of the categories 2 to 5 ( 8 farms total). Within each selected farm, 2 to 4 milk meters were randomly selected based on the lactating herd size (Table 1). During one round of the routine DHI sampling procedure, 2 simultaneous milk samples (30 $\mathrm{mL}$ each), one hand-collected at the beginning of milking (after udder preparation) and the other from the corresponding milk meter, were taken from all lactating cows $(\mathrm{n}=236)$ that were milked at the selected meters $(\mathrm{n}=26)$. The sequence of the cows milked using each meter was precisely recorded by the project personnel.

\section{Laboratory Testing}

Meter-collected samples were submitted to the Maritime Quality Milk (MQM) laboratory located at the Atlantic Veterinary College, University of Prince Edward Island, in Charlottetown, Canada, after undergoing the standard quality and components analyses in a local DHI laboratory (PEI Analytical Laboratory, Charlottetown, Prince Edward Island, Canada). Handcollected samples were directly submitted to the MQM laboratory. All samples were tested for BLV antibodies using a commercial indirect ELISA kit (Svanovir BLV gp51-Ab, Svanova, Uppsala, Sweden). The test results were reported as percent positivity $(\mathbf{P P})$ values $[\mathrm{PP}=$ $\left(\mathrm{OD}_{\text {corrected }}\right.$ sample $/ \mathrm{OD}_{\text {corrected }}$ positive control $) \times 100$, where $\mathrm{OD}=$ optical density], and the recommended cut-off value of the kit for individual milk samples was 10.

\section{Statistical Analyses}

All of the statistical analyses were conducted in Stata 13.1 (StataCorp, College Station, TX).

Agreement. To evaluate the overall agreement between hand $\left(\mathbf{P P}_{\text {hand }}\right)$ and meter $\left(\mathbf{P} \mathbf{P}_{\text {meter }}\right)$ test results, a scatter diagram was produced and the concordance correlation coefficient was calculated. In addition, the overall agreement of the dichotomized results (at the recommended cut-off of 10) from the 2 types of samples was explored using McNemar's Chi-squared test and Cohen's kappa coefficient (Dohoo et al., 2009).

Carryover Effects. To determine the potential carryover effects of BLV antibodies, all cows that had been preceded by other cows at the same meters contributed to building a multivariable linear regression 
model. It was assumed that the difference between meter- and hand-collected ELISA values for each cow $\left(\mathrm{Y}=\mathrm{PP}_{\text {meter }}-\mathrm{PP}_{\text {hand }}\right)$ was a function of hand value for the cow $\left(\mathrm{PP}_{\text {hand }} ; \mathrm{X}_{1}\right)$, meter value from the preceding cow $\left(\mathrm{PP}_{\text {meter-1 }} ; \mathrm{X}_{2}\right)$, and their interaction term $\left(\mathrm{X}_{1} \mathrm{X}_{2}\right)$. The final model was

$$
\mathrm{Y}=\beta_{0}+\beta_{1} \mathrm{X}_{1}+\beta_{2} \mathrm{X}_{2}+\beta_{3} \mathrm{X}_{1} \mathrm{X}_{2}+\varepsilon,
$$

where $\beta_{0}$ is the intercept; $\varepsilon$ is the residuals of the model; and other $\beta$ are regression coefficients corresponding to the terms defined above; Y represents the potential carryover effects, as well as other random measurement variations. A 1-sample $t$-test was also performed to determine whether the average of the difference $(\mathrm{Y})$ values for the cows which were milked first per meter (first-per-meter cows; $\mathrm{n}=25,1$ missing) was significantly different from zero.

Carryover in Meter-Positive Samples. To specifically explore the effect of carryover on generating extra false-positive results to BLV infection, all meter-positive cows $\left(\mathrm{PP}_{\text {meter }} \geq 10\right)$ that were preceded by other cows at the same meters were extracted (n $=133 ; 3$ missing values). The difference between the hand value of each cow $\left(\mathrm{PP}_{\text {hand }}\right)$ and the hand value from the previous cow $\left(\mathrm{PP}_{\text {hand-1 }}\right)$ at the same meter was then calculated $\left(\mathrm{PP}_{\text {hand }}-\mathrm{PP}_{\text {hand-1 }}\right)$. A logistic regression model was built to determine the effect of this difference, as a surrogate for potential carryover, on the odds of obtaining a false positive diagnosis (positive in meter- but negative in hand-collected samples) compared with the odds of a true positive diagnosis (positive in both types of the samples).

ELISA Cut-Off. Finally, to explore new ELISA cut-off values that would minimize the proportion of false positives in the routine application of the test on meter samples, a 2-graph receiver operating characteristic analysis was carried out (Dohoo et al., 2009). The optimal adjusted cut-off for meter-collected samples was determined using the dichotomized hand-collected results as the reference standard. Based on the original kit and the adjusted cut-off values for the meter-collected samples, 3 categories of ELISA results (negative, suspicious, and positive) were defined for further screening purposes.

\section{RESULTS}

Descriptive data on study herds and samples are presented in Table 1. Lactating herd size in the studied dairy herds ranged from 46 to 126 . Proportional to herd size, 12 to 48 cows from each herd were sampled in the study for a total of 236 cows (all Holstein). Based on the recommended cut-off of the test, 110 cows (46.6\%) in the hand-collected samples and 136 cows $(57.6 \%)$ in the meter-collected samples were found to be positive.

\section{Agreement}

The McNemar's Chi-squared test was highly significant $(P<0.001)$, which suggested that the proportion of positive test results disagreed between the dichotomized hand- and meter-collected results. Because the McNemar's test was significant, the Cohen's kappa result is not presented. However, when examined on a continuous basis, a relatively strong correlation (concordance correlation coefficient $=0.905$ ) was noted between the 2 sets of the PP values. This relationship is illustrated in Figure 1.

\section{Carryover Effects}

The final linear model included 207 cows (25 first per meter cows and 4 cows with unavailable previous values). The interaction term between $\mathrm{PP}_{\text {hand }}$ and $\mathrm{PP}_{\text {meter-1 }}$ was highly significant $(P<0.001)$, indicating that the behavior of antibody carryover against the preceding cows' meter titers depended on different levels of cows' hand titers. To clarify the interaction, a graph was produced to illustrate changes in $\mathrm{Y}$ for the cows versus titer of the preceding cows $\left(\mathrm{PP}_{\text {meter-1 }}\right)$ at 3 different constant levels of $\mathrm{PP}_{\text {hand }}$ values (Figure 2). From the graph, for cows with the low levels of BLV antibody titer (e.g., $\mathrm{PP}_{\text {hand }}<30$; including all negatives), antibody carryover $(\mathrm{Y})$ increased as the titer of their preceding cows increased. As the titer of cows increased (e.g., $\mathrm{PP}_{\text {hand }}>60$ ), antibody carryover started showing

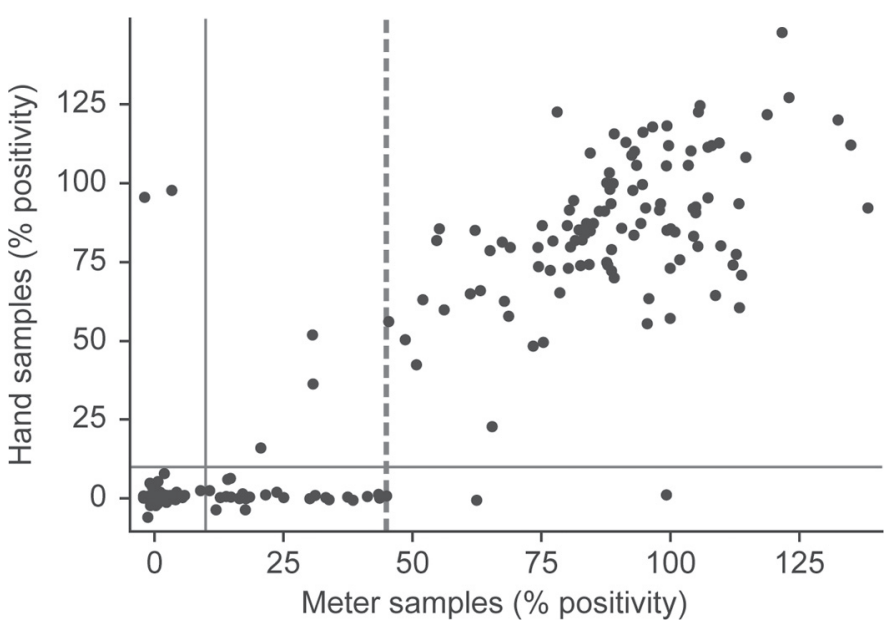

Figure 1. Scatter plot of milk-ELISA results (percent positivity) for antibodies against bovine leukemia virus in paired hand- and meter-collected milk samples from 236 study cows. The 2 overlaid solid lines represent the recommended cut-off of 10 , and the dashed line represents the adjusted cut-off of 45 . 


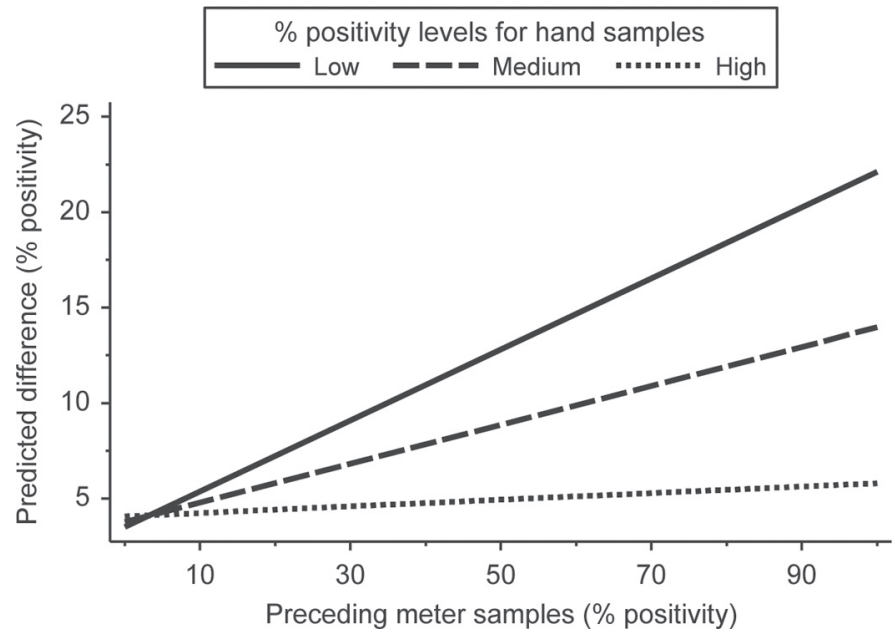

Figure 2. Interaction plot illustrating the relationship between predicted difference of paired hand- and meter-collected ELISA results (y-axis; $\left.\mathrm{PP}_{\text {meter }}-\mathrm{PP}_{\text {hand }}\right)$ and meter-collected results of preceding cows (x-axis; $\mathrm{PP}_{\text {meter-1 }}$ ) at different levels of hand-collected results $\left(\mathrm{PP}_{\text {hand }}\right)$ for antibodies against bovine leukemia virus in 207 study cows. Low, medium, and high levels of antibody represent 0,30 , and 60 percent positivity values for hand-collected samples, respectively.

a weaker positive association with changes in the titer of previous cows until it gradually faded toward being insignificant. The $t$-test for the first per meter cows resulted in a $P$-value of 0.289 , indicating the average of $Y$ values was not significantly different from zero. In other words, when there was no possibility for carryover at all, the average of measurement variations between hand- and meter-collected values would be minor.

\section{Carryover in Meter-Positive Samples}

Based on the logistic model, the carryover effect on positive samples was highly significant $(P<0.001)$. With each unit (percent positivity) increase in $\mathrm{PP}_{\text {hand }}$ - $\mathrm{PP}_{\text {hand-1 }}$, the odds of getting a false diagnosis decreased by 0.05 ; that is, preceding by a high-titer cow at the same meter significantly increased the odds of false-positive results in the subsequent meter-positive samples.

\section{ELISA Cut-Off}

Figure 3 illustrates the 2-graph receiver operating characteristic curve (sensitivity or specificity vs. all possible cut-offs). Based on the graph, the cut-off for optimizing test characteristics would be achieved at a $\mathrm{PP}$ of approximately 45 . If the later cut-off was used alone, we would gain a quite higher specificity (from 0.777 to 0.984 ), whereas the loss in sensitivity would be relatively negligible (from 0.982 to 0.955 ). Consequently, the number of false-positive results substantially

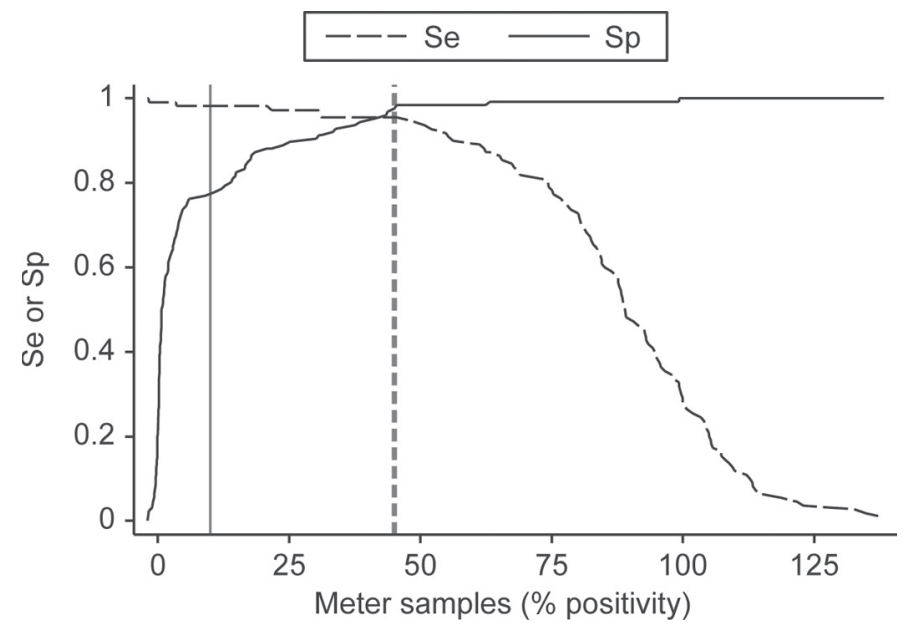

Figure 3. Sensitivity (Se) or specificity ( $\mathrm{Sp}$ ) plot against all possible cut-off values for paired hand- and meter-collected milk-ELISA results for bovine leukemia virus antibodies in 236 study cows. Hand samples were the dichotomized reference standard to the continuous meter values (percent positivity). The vertical solid line represents the recommended cut-off of 10 , and the vertical dashed line represents the adjusted cut-off of 45 .

reduced (from 28/136 to $2 / 106$ ), whereas the effect on the false negatives was relatively small (increased from $2 / 100$ to 6/130). As presented in Table 2, 3 categories of the ELISA values were defined as (1) negative $\left(\mathrm{PP}_{\text {meter }}<10\right)$; $(2)$ doubtful or suspicious $\left(10 \leq \mathrm{PP}_{\text {meter }}\right.$ $\leq 45)$; and $(3)$ positive $\left(\mathrm{PP}_{\text {meter }}>45\right)$. Thirty samples were located within the suspicious range, and $86.7 \%$ $(26 / 30)$ of them were falsely positive (i.e., negative in hand-collected samples), whereas only $1.9 \%(2 / 106)$ of the samples within the positive range were falsely positive.

\section{DISCUSSION}

In our study, we found a significant carryover when cows with high BLV antibody titers preceded low-titer (e.g., true negative) cows at the same meters. For instance, based on the interaction plot, if a negative cow was preceded by a positive cow with medium-to-high titer (e.g., >50), adequate levels of carried BLV antibodies could be detected and led to a false positive diagnosis. In high-prevalence herds, where a higher chance of meter contamination and therefore risk of carryover exists, a substantial number of noninfected cows may be falsely diagnosed at the published cut-off. Different studies have evaluated the importance of carryover of milk components (e.g., fat, protein, and SCC) in samples from automated milking systems (Dill, 1974; Ordolff, 1997; Friggens and Rasmussen, 2002; Løvendahl and Bjerring, 2006). For conventional milking meters, Dill (1974) indicated a significant carryover effect 
Table 2. Cross-classification of milk-ELISA results for antibodies against bovine leukemia virus (BLV) from paired hand- and meter-collected samples in 236 study cows from Prince Edward Island, Canada

\begin{tabular}{lcccc}
\hline & \multicolumn{4}{c}{ Meter samples $^{1}$} \\
\cline { 2 - 4 } $\begin{array}{l}\text { Hand } \\
\text { samples }\end{array}$ & $\begin{array}{c}\mathrm{PP}_{\text {meter }}<10 \\
\text { (Negative) }\end{array}$ & $\begin{array}{c}10 \leq \mathrm{PP}_{\text {meter }} \leq 45 \\
\text { (Suspicious) }\end{array}$ & $\begin{array}{c}\mathrm{PP}_{\text {meter }}>45 \\
\text { (Positive) }\end{array}$ & Total \\
\hline Negative & 98 & 26 & 2 & 126 \\
Positive & 2 & 4 & 104 & 110 \\
Total & 100 & 30 & 106 & 236 \\
\hline
\end{tabular}

${ }^{1}$ The range of ELISA results in percent positivity for meter-collected samples $\left(\mathrm{PP}_{\text {meter }}\right)$ has been divided into 3 categories at the 2 cut-off values of 10 (original) and 45 (adjusted).

on the milk fat when the previous sample was as much as $1 \%$ higher or $2 \%$ lower in fat than the tested sample. Byrem et al. (2013) stated that when measuring endogenous milk components such as fat and protein, the influence of existing carryover was negligible, but this effect could particularly be important on exogenous components (such as antibodies or other diagnostic targets). They further suggested that carryover of $3 \%$ milk between samples can result in detectable levels of antibody in milk in an uninfected cow if preceded by an infected cow having milk antibody levels at relatively low levels (Byrem et al., 2013). Despite this, we were not able to find any published data on antibody carryover in conventional milk meters.

To account for BLV antibody carryover, we defined 3 levels of sample results for optimizing the performance of the current ELISA test. Samples with $\mathrm{PP}_{\text {meter }}<10$ were negative and those $>45$ were positive, whereas samples with $10 \leq \mathrm{PP}_{\text {meter }} \leq 45$ were considered a suspicious category. As indicated in Table 2, the majority of cows in the suspicious range were in fact negative. Hence, if a cow falls within this range, a retest should be requested. The retest sample should be a direct handcollected milk sample or a serum sample. Subsequently, the second test result should be interpreted based on the original dichotomous cut-off of the kit. Putting this strategy in place, a substantial number of false positive diagnoses could efficiently be prevented without loss in sensitivity (i.e., no extra false negatives are generated). This gain can economically be significant when test and removal, or test and segregation programs for BLV infection, are pursued. For herds with medium or high levels of within-herd prevalence, such as many dairy farms in North America, management strategies for controlling BLV are preferred due to considerable cost (and impracticality) of removal and segregation programs (Sandev et al., 2000; Bartlett et al., 2014). Therefore, our recommendations could provide a more cost-effective screening or monitoring tool for accomplishing the control measures.
Other methods for controlling the carryover effects have also been proposed, such as diluting meter milk samples before testing (Walsh et al., 2013). This method could potentially cause extra false-negative results for low-titer positive samples and interfere with precise measurements on milk components during DHI procedures. A potentially useful method for avoiding carryover effects could be recommending the rinsing of milk meters between cows. This procedure is likely to reduce carryover, but may be difficult to consistently adhere to because of time pressures during milking on many dairy farms. Despite the challenges identified in this research, DHI-collected samples offer many economical and logistic advantages for screening for BLV (or other common pathogens in dairy cattle).

Overall, we had only $2(0.8 \%)$ false-negative results (i.e., negative in meter- but positive in hand-collected samples). These were identified as outliers during the statistical analyses; that is, the 2 cows with a large difference between their hand and meter ELISA values $(\mathrm{Y}>40)$. However, these 2 cows were kept in our analyses, because (1) refitting the linear model without the 2 outliers did not affect the conclusions and (2) we could not find any logical reason (e.g., obvious laboratory mistakes) for removing them. One of the false negative samples was from a first-per-meter cow (i.e., no possibility for carryover), whereas the other one was preceded by a positive cow. Moreover, the linear model suggested that the potential carryover effect was not significant when low-titer (or even medium-titer) positive cows were preceded by low-titer cows at the same meters. According to our results, therefore, the potential diluting effects of carryover on generating extra false-negative results would not be concerning. Hence, we did not consider changing the interpretation of the lower ELISA cut-off of 10.

Our study was only focused on carryover of BLV antibodies using an ELISA test. However, the issue of carryover might be of concern in diagnosing other important infectious diseases of dairy cattle through 
the DHI process, specifically when methods with high analytical sensitivity such as ELISA and PCR are applied. Therefore, conducting similar studies on the other commonly tested pathogens is recommended to clarify and mitigate such detrimental effects.

\section{CONCLUSIONS}

Carryover of BLV antibodies at shared milk meters was significant. For low-titer cows (e.g., negatives), the carryover effect was positively associated with the titer of the preceding cows. This could result in generating false-positive results in the BLV antibody-ELISA test on meter-collected samples from DHI procedures. For meter-collected samples, if we only rely on the dichotomous test results with the original cut-off, the consequences can be economically substantial. Thus, defining a suspicious category for the ELISA titers and recommending a retest on the samples falling within this range would be very helpful in reducing the false positive rate.

\section{ACKNOWLEDGMENTS}

The authors gratefully acknowledge the contribution of all parties to this project, including summer students, study farms, MQM laboratory (Charlottetown, PE) personnel, specifically Natasha Robinson, and Valacta (Sainte-Anne-de-Bellevue, QC). This study was kindly funded by the MQM laboratory, Valacta, Dairy Farmers of Prince Edward Island, New Brunswick and Nova Scotia, the New Brunswick Department of Agriculture and Agriculture and Agri-Food Canada through the Agricultural Adaptation programs in Prince Edward Island and Nova Scotia.

\section{REFERENCES}

Attalla, S. A., A. J. Seykora, J. B. Cole, and B. J. Heins. 2010. Genetic parameters of milk ELISA scores for Johne's disease. J. Dairy Sci. 93:1729-1735.

Bartlett, P. C., L. M. Sordillo, T. M. Byrem, B. Norby, D. L. Grooms, C. L. Swenson, J. Zalucha, and R. J. Erskine. 2014. Options for the control of bovine leukemia virus in dairy cattle. J. Am. Vet. Med. Assoc. 244:914-922.

Byrem, T. M., B. D. Voisinet, and S. J. Sievert. 2013. Milk Recording Samples-Multiple Analyses, Multiple Challenges. ICAR Technical Meeting. ICAR, Aarhus, Denmark.
Dill, C. W. 1974. Sample carry-over in the Milko-tester procedure for consecutive milk fat determinations. J. Dairy Sci. 57:129-131.

Dohoo, I. R., S. W. Martin, and H. Stryhn. 2009. Veterinary Epidemiologic Research. 2nd ed. VER, Inc. Charlottetown, PEI, Canada.

Erskine, R. J., P. C. Bartlett, T. M. Byrem, C. L. Render, C. Febvay, and J. T. Houseman. 2012. Using a herd profile to determine age-specific prevalence of bovine leukemia virus in Michigan dairy herds. Vet. Med. Int. 2012:350374.

Friggens, N. C., and M. D. Rasmussen. 2002. Milk quality assessment in automatic milking systems: Accounting for the effects of variable intervals between milkings on milk composition. Livest. Prod. Sci. $73: 45-54$

Houe, H., J. C. Baker, R. K. Maes, H. Wuryastuti, R. Wasito, P. L. Ruegg, and J. W. Lloyd. 1995. Prevalence of cattle persistently infected with bovine viral diarrhea virus in 20 dairy herds in two counties in central Michigan and comparison of prevalence of antibody-positive cattle among herds with different infection and vaccination status. J. Vet. Diagn. Invest. 7:321-326.

Løvendahl, P., and M. A. Bjerring. 2006. Detection of carryover in automated milk sampling equipment. J. Dairy Sci. 89:3645-3652.

Ordolff, D. 1997. Technical note: Experiments on automatic preparation of milk samples in connection with milking robots. Comput. Electron. Agric. 17:133-137.

Richardson, G. F., and E. B. Macaulay. 1992. The prevalence of bovine leukemia virus infection in dairy cows on Prince Edward Island. Can. Vet. J. 33:188-189.

Samagh, B. S., and J. A. Kellar. 1982. Seroepidemiological survey of bovine leukaemia virus infection in Canadian cattle. Curr. Top. Vet. Med. Anim. Sci. 15:397-412.

Sandev, N., N. Kostadinova, and I. Zarkov. 2000. Economic problems concerning enzootic bovine leukosis. Agric. Econ. Manag. 45:3841.

Sargeant, J. M., D. F. Kelton, S. W. Martin, and E. D. Mann. 1997. Associations between farm management practices, productivity, and bovine leukemia virus infection in Ontario dairy herds. Prev. Vet. Med. 31:211-221.

Sorge, U. S., K. Lissemore, R. Cantin, and D. F. Kelton. 2011. Milk ELISA status for bovine leukosis virus infection is not associated with milk production in dairy cows. J. Dairy Sci. 94:5062-5064.

VanLeeuwen, J. A., L. A. Forsythe, A. Tiwari, and R. Chartier. 2005. Seroprevalence of antibodies against bovine leukemia virus, bovine viral diarrhea virus, Mycobacterium avium subspecies paratuberculosis, and Neospora caninum in dairy cattle in Saskatchewan. Can. Vet. J. $46: 56-58$.

VanLeeuwen, J. A., G. P. Keefe, R. Tremblay, C. Power, and J. J. Wichtel. 2001. Seroprevalence of infection with Mycobacterium avium subspecies paratuberculosis, bovine leukemia virus, and bovine viral diarrhea virus in maritime Canada dairy cattle. Can. Vet. J. $42: 193-198$.

VanLeeuwen, J. A., T. L. Whiting, J. C. Plaizier, and A. Tiwari. 2006. Seroprevalences of antibodies against bovine leukemia virus, bovine viral diarrhea virus, Mycobacterium avium subspecies paratuberculosis, and Neospora caninum in beef and dairy cattle in Manitoba. Can. Vet. J. 47:783-786.

Walsh, R. B., D. F. Kelton, S. K. Hietala, and T. F. Duffield. 2013. Evaluation of enzyme-linked immunosorbent assays performed on milk and serum samples for detection of neosporosis and leukosis in lactating dairy cows. Can. Vet. J. 54:347-352. 